\title{
A Descriptive Study on Aeroallergen Sensitivity Pattern in Children with Bronchial Asthma and/or Allergic Rhinitis
}

\author{
Saket Yadav ${ }^{1}$ Madhu Mathur $^{1}$ Gunjan Agarwal ${ }^{1}$ Abhishek Kumar Sharma ${ }^{10}$ \\ ${ }^{1}$ Department of Pediatrics, Mahatma Gandhi Medical College \& \\ Hospital, Jaipur, Rajasthan, India \\ Address for correspondence Abhishek Kumar Sharma, DCH, DNB, \\ Department of Pediatrics, Mahatma Gandhi Medical College \& \\ Hospital, Sitapura, Jaipur 302022, Rajasthan, India \\ J Child Sci 2020;10:e48-e52. \\ (e-mail: draksharma82@gmail.com).
}

\begin{abstract}
Keywords

- reactive airway diseases

- skin prick test

- house dust mite

- storage mite
\end{abstract}

Background The growing prevalence of allergy and asthma in India has become a major health concern, with symptoms ranging from mild rhinitis to severe asthma, and aeroallergens play a major role in the pathogenesis of reactive airway diseases. The distribution of aeroallergen and the knowledge of allergen sensitivity pattern in northern India (Rajasthan) are limited. The aim of our study was to determine the prevalence of various aeroallergens in children with bronchial asthma and/or allergic rhinitis by skin prick test at a tertiary care center in Jaipur, Rajasthan, India.

Methods Children who had presented to the Department of Pediatrics (outpatient department and inpatient department), Mahatma Gandhi Medical College, Jaipur, from January 2018 to June 2019 fulfilling the inclusion criteria, were included in this prospective study. A total of 15 antigens were used. Skin prick testing was performed as per standard protocol.

Result Among total 60 children with respiratory allergic diseases, overall the highest percentage of skin prick test positivity was found among house dust mite (66.6\%), storage mite (41.6\%), wheat (33.3\%), animal dander (30\%), and Kentucky bluegrass (26.6\%), in that order.

Conclusion It is advised to avoid common inhaled allergens found with SPT in our region in children with allergic airway diseases.

\section{Introduction}

Reactive airway diseases (RADs) such as bronchial asthma (BA) and allergic rhinitis (AR) represent a major burden worldwide from both an epidemiological and economical point of view. ${ }^{1}$ A survey conducted by the World Allergy Organization estimated that a worldwide prevalence of AR is 16 to $25 \%$ and that of BA is 6 to $15 \%{ }^{2}$ Allergic disorders are not just a public health problem for developed countries, but their prevalence is also rising dramatically in developing countries like India that has an uprising trend in terms of both prevalence and severity. ${ }^{3}$ Children are bearing the greatest burden of the rising trend of these diseases. Asthma

received

April 27, 2020

accepted after revision

May 14, 2020
DOI https://doi.org/

10.1055/s-0040-1713625. ISSN 2474-5871. is the commonest chronic disorder among children, and the prevalence has been estimated to range from 3 to $38 \%$ in children. ${ }^{4}$ Aeroallergens play a major role in the pathogenesis of RAD. Pollens, molds, house dust mites (HDMs), fungal spores, and pets are one of the most common allergens prevalent in India. Skin prick test (SPT) is considered the gold standard for the diagnosis of immunoglobulin E (IgE) mediated type 1 allergy. Allergen evaluation is required for allergen-specific therapy but does not depend on allergen dispersion due to climate. India is expected to have a wide range of allergens as it is a country with diverse climatic and geographic conditions. Data are scarce regarding allergen sensitivity in Rajasthan, especially in children. Hence, our
Copyright @ 2020 Georg Thieme Verlag License terms KG Stuttgart · New York 
study was conducted to identify the pattern of allergen sensitivity among children with BA and/or AR using SPT, which would further help in appropriate diagnosis, disease monitoring, and treatment of these children.

\section{Materials and Methods}

This study aimed to determine the prevalence of various aeroallergens in children with BA and/or AR by SPT at Mahatma Gandhi Medical College (MGMC) in Jaipur, Rajasthan. The study design was a prospective cross-sectional study. The study place was the Department of Pediatrics (Outpatient department [OPD] and inpatient department), Mahatma Gandhi Medical College, Jaipur, Rajasthan, which is a 1,000-bed tertiary care center. The study period was January 2018 to June 2019. The study population was 60 children fulfilling inclusion criteria who presented to the Department of Pediatrics, MGMC.

\section{Inclusion Criteria}

The inclusion criteria were children attending the Pediatrics OPD of Mahatma Gandhi Hospital, children diagnosed with $\mathrm{BA}$ and/or AR according to the GINA and ARIA guidelines, and age between 5 and 15 years of either sex.

\section{Exclusion Criteria}

The inclusion criteria were as follows:

- Children having skin diseases such as eczema, dermographism, severe dermatitis, or any other chronic skin diseases.

- Immune compromised children, those with HIV, those with nephrotic syndrome, and those on oral steroids ( $>2 \mathrm{mg} / \mathrm{kg} /$ day for $>2$ weeks).

- Children having tuberculosis, diabetes, or any other chronic systemic illness.

- Patients in acute exacerbation of BA.

- Refusal to give consent to be a part of the study or uncooperative during the SPT.

After ethical clearance obtained from the Institute's Ethical Committee (Ethic No. MGHCH/IEC/JPR/2018/05) and informed parental/guardian consent taken from all eligible study patients, a cross-sectional prestructured proforma-based study was conducted. The proforma included demographic profile, symptomatology, examination, severity, and control of $\mathrm{BA} / \mathrm{AR}$ along with investigation reports. Investigations included were complete blood count, total eosinophil count, specific IgE test, chest X-ray, peak expiratory flow rate, and SPT.

SPT panel consisted of the following groups of aeroallergens using standard allergen extracts from Merck Allergo-SPT: pollens, grasses, mites, dander, and molds. SPT was performed as per the standard protocol. The allergens used for SPT were Dermatophagoides pteronyssinus (HDM), Chenopodium album (lambs quarter), Ambrosia artemisiifolia (ragweed), Plantago lanceolata (English plantain), Cynodon dactylon (Bermuda grass), Lolium perenne (ryegrass), Poa pratensis (Kentucky bluegrass), Robinia pseudoacacia (locust black), Triticum aestivum (wheat), Zea mays (corn), Aspergillus Fumigatus, Helmin- thosporium halodes, animal epithelia (animal dander), Acarus siro (storage mite), and Hordeum vulgare (barley).

\section{Method}

SPT was performed by applying a drop of antigen on the healthy skin on the volar surfaces of the forearm and pricking it with a lancet with a point length of $1 \mathrm{~mm}$. Reading was interpreted after 15 to 20 minutes. Assessment of skin reactivity was performed by calculating the mean diameter as $(D+d) / 2$, where $D=$ the largest diameter and $d=$ orthogonal or perpendicular diameter at the largest width of $D$ after 15 to 20 minutes. SPT interpretation: mean wheal diameter $1+=<3 \mathrm{~mm}, 2+=3$ to $5 \mathrm{~mm}, 3+=5$ to $7 \mathrm{~mm}, 4+=7$ to $9 \mathrm{~mm}$. A positive result ( $2+$ and above) to a specific allergen is indicated by a mean wheal diameter measuring $3 \mathrm{~mm}$ or more, greater than the negative control (buffered saline). If patients were on oral drugs including antihistaminic (cetirizine, hydroxyzine) or topical steroid, SPT was withheld and performed 7 days after stopping the drug. If patients were on short-term oral steroids ( $<2 \mathrm{mg} / \mathrm{kg} /$ day for $<10$ days), SPT was withheld and performed 3 days after stopping the drug as it can give false-negative SPT results. If patients were on other drugs such as inhaled/topical steroids, beta-agonists (salbutamol, formoterol, terbutaline), and montelukast, SPT was performed and drugs were continued as it would not interfere with SPT interpretation.

\section{Results}

-Table 1 shows that among 60 children with RADs, the majority of children (58.3\%) belonged to the age group of 5 to 10 years, and the remaining (41.7\%) belonged to the age group of 11 to 15 years.

- Table 2 shows that in our study, males (76.7\%) were higher recorded as compared with females (23.3\%). Among 60 children, $51.7 \%$ were from the urban locality and $48.3 \%$ were from rural backgrounds. Out of 60 patients, 38 (63.3\%) patients have perennial distribution, whereas $36.7 \%$ of patients have seasonal distribution. Among the total children in the study, $55 \%$ had a positive family history of atopy and $45 \%$ had a negative family history.

- Table 3 shows that in our study, there was $60 \%$ positivity, that is, 36 patients have positive SPTs.

- Table 4 shows SPT interpretation in our study. There was $1+$ in 24 patients (40\%), $2+$ in 2 patients (3.33\%), $3+$ in 18 patients (30\%), and $4+$ in 16 patients (26.66\%).

-Table 5 shows that high serum IgE level $(>500 \mathrm{IU} / \mathrm{ml})$ was recorded in 44 (73.33\%) patients.

Table 1 Age distribution of the children

\begin{tabular}{|l|l|l|}
\hline Age $(\mathrm{y})$ & Frequency & Percentage \\
\hline $5-10$ & 35 & 58.3 \\
\hline $11-15$ & 25 & 41.7 \\
\hline Total & 60 & 100 \\
\hline Mean \pm SD & $9.28 \pm 2.94$ & \\
\hline
\end{tabular}

Abbreviation: SD, standard deviation. 
Table 2 Demographic profile distribution of children

\begin{tabular}{|l|l|l|l|}
\hline Variants & Variable 1 & Variable 2 & Total \\
\hline Gender & Male & Female & \\
\hline Frequency & 46 & 14 & 60 \\
\hline Percent & 76.7 & 23.3 & 100 \\
\hline Geographical area & Rural & Urban & \\
\hline Frequency & 29 & 31 & 60 \\
\hline Percent & 48.3 & 51.7 & 100 \\
\hline Perennial/seasonal & Perennial & Seasonal & \\
\hline Frequency & 38 & 22 & 60 \\
\hline Percent & 63.3 & 36.7 & 100 \\
\hline Family history of atopy & Yes & No & \\
\hline Frequency & 33 & 27 & 60 \\
\hline Percent & 55 & 45 & 100 \\
\hline
\end{tabular}

Table 3 Skin prick test result

\begin{tabular}{|l|l|l|}
\hline & Frequency & Percentage \\
\hline Negative & 24 & 40 \\
\hline Positive & 36 & 60 \\
\hline Total & 60 & 100 \\
\hline
\end{tabular}

Table 4 SPT interpretation

\begin{tabular}{|l|l|l|}
\hline & Frequency & Percentage \\
\hline $1+$ & 24 & 40 \\
\hline $2+$ & 2 & 3.33 \\
\hline $3+$ & 18 & 30 \\
\hline $4+$ & 16 & 26.66 \\
\hline Total & 60 & 100 \\
\hline
\end{tabular}

Abbreviation: SPT, skin prick test.

- Table 6 shows that HDM (60\%) was recorded highest followed by storage mite (41.6\%), wheat (33.3\%), animal dander (30\%), and Kentucky bluegrass (26.6\%). Many positive patients showed polysensitization.

\section{Discussion}

Our study aimed to determine the aeroallergen prevalence in both BA and/or AR pediatric patients in the age group 5 to 15 years. The age of patients ranged from 5 to 15 years, and the mean age was 9.28 years. Raj et $\mathrm{al}^{5}$ also found a mean age of 9.2 years in the Indian population.

Our study indicates that males have a higher prevalence of concomitant asthma as compared with females. Similar trends were seen in a Finnish study, where the risk of asthma was significantly higher in males than in females. ${ }^{6}$ Our study has a male predominance, with $76.7 \%$ males and $23.3 \%$ females. It is consistent with finding by Prasad et $\mathrm{al}^{7}$ and Dave and Srivastava. ${ }^{8}$ This gender difference in the study
Table 5 Serum IgE (high/normal)

\begin{tabular}{|l|l|l|}
\hline & Frequency & Percentage \\
\hline High & 44 & 73.33 \\
\hline Normal & 16 & 26.66 \\
\hline Total & 60 & 100 \\
\hline
\end{tabular}

Abbreviation: IgE, immunoglobulin $\mathrm{E}$.

Table 6 Allergen-wise distribution of the study

\begin{tabular}{|l|l|l|}
\hline & Frequency & Percentage \\
\hline $\begin{array}{l}\text { Dermatophagoides } \\
\text { pteronyssinus } \\
\text { (house dust mite) }\end{array}$ & 36 & 60 \\
\hline $\begin{array}{l}\text { Ambrosia artemisiifolia } \\
\text { (ragweed) }\end{array}$ & 10 & 16.66 \\
\hline $\begin{array}{l}\text { Plantago lanceolata } \\
\text { (English plantain) }\end{array}$ & 14 & 23.3 \\
\hline $\begin{array}{l}\text { Cynodon dactylon } \\
\text { (Bermuda grass) }\end{array}$ & 12 & 20 \\
\hline Lolium perenne (ryegrass) & 10 & 16.66 \\
\hline $\begin{array}{l}\text { Poa pratensis } \\
\text { (Kentucky bluegrass) }\end{array}$ & 16 & 26.6 \\
\hline $\begin{array}{l}\text { Robinia pseudoacacia } \\
\text { (locust black) }\end{array}$ & 10 & 16.66 \\
\hline Triticum aestivum (wheat) & 20 & 33.3 \\
\hline Zea mays (corn) & 12 & 20 \\
\hline Aspergillus fumigatus (fungus) & 8 & 13.3 \\
\hline $\begin{array}{l}\text { Helminthosporium halodes } \\
\text { (fungus test) }\end{array}$ & 9 & 15 \\
\hline $\begin{array}{l}\text { Animal epithelia } \\
\text { (animal dander) }\end{array}$ & 18 & 30 \\
\hline Acarus siro (storage mite) & 25 & 1.6 \\
\hline $\begin{array}{l}\text { Hordeum vulgare } \\
\text { (barley [cereal grain]) }\end{array}$ & 8 & \\
\hline
\end{tabular}

could be because of gender bias in India, that is, bringing a male child more often to the hospital than a female child.

The patients of asthma and/or rhinitis had a positive family history of atopy (55\%). This is consistent with Moitra et al's ${ }^{9}$ study, where $40.19 \%$ of diseases mediated by allergy were strongly familial. Ibekwe and Ibekwe ${ }^{10}$ found in their study on AR patients that a family history of atopy was present in $56.8 \%(n=42)$ of AR cases. Han et al $^{11}$ found the family history to be positive in $52.5 \%(n=906)$ cases of asthma, similar to our study.

In our study, perennial activities were $63.3 \%$. This was consistent with Moitra et al's, ${ }^{9}$ which shows $67.64 \%$. In a study by Sharma et al, ${ }^{12}$ out of 134 patients of AR and asthma, 69 (51.49\%) had seasonal variation and the rest 65 (48.51\%) had perennial variation, whereas our study shows contrary results. Similarly, Spinozzi et $\mathrm{al}^{13}$ found in their study that $71.2 \%(n=222)$ cases of AR showed seasonal trends. Observation by Kumar ${ }^{14}$ on seasonality of asthma in North Indian patients showed that seasonal and perennial symptoms were 
equal, whereas in asthma patients of our study, $63.6 \%$ $(n=89)$ cases showed perennial symptoms.

In our study, among 60 children in whom SPT was performed, 36 children (60\%) came out to be positive. This was consistent with Kumar et al's ${ }^{15}$ study, which shows polysensitization in $71.5 \%$. Raj et al $^{5}$ also found $55.5 \%$ positive SPT out of 180 children with at least $37.8 \%$ positive to more than one allergen. Our study was not consistent with Rasool et al's ${ }^{16}$ study, which shows that positivity to the single allergen is $0.5 \%$. Various studies from India and abroad showed a high prevalence of SPT positivity. Studies such as those by Siroux et $\mathrm{al}^{17}$ found $88.2 \%(n=122)$ SPT positivity, Raj et $\mathrm{al}^{5}$ found $55.6 \%(n=100)$ SPT positivity, Prasad et al ${ }^{7}$ $89.5 \%(n=43)$ SPT positivity, and Kumar et al $^{18}$ found $71.3 \%$ $(n=3040)$ SPT positivity.

In our study, $60 \%$ of children with allergic diseases were positive to Dermatophagoides pteronyssinus (HDM) and 13.3\% to Aspergillus fumigatus. This was consistent with other Indian studies such as those by Moitra et $\mathrm{al}^{9}$, Prasad et $\mathrm{al}^{7}{ }^{7}$ which shows HDM as a predominant allergen (86.27, and 25 , respectively). Mathur and Mathur ${ }^{19}$ showed that $21 \%$ of patients had house dust allergen positivity in the population of Western Rajasthan. Dey and Chakraborty 20 found Bermuda grass as the causative agent in $22.22 \%$ of AR cases.

The most common aeroallergens in our population were the pollens. Most of the patients were sensitive to one or more species of pollens. The reason could be that inhabitants were living in close proximity to farmlands, meadows, and forest areas. The surroundings in our country were highly enriched with natural flora. The patterns of aeroallergens in the environment widely differ in different localities and are affected by seasonal changes, particularly when they affect pollen. Duc et $\mathrm{al}^{21}$ had also found house dust to be the most common allergen in patients of rhinitis with BA followed by grass pollens and animal dander. There were a few patients who were sensitive to sheep wool, as they used to deal with sheep husbandry. Neither of the patients was tested positive for dog or cat animal allergy, as there is no custom of keeping such animals as a pet. Usually, our people avoid coming into contact with dogs and cats.

In the study, Prasad et $\mathrm{al}^{7}$ found that the common offending allergens were insects $(21.8 \%[n=10])$ followed by dusts (11.9\% [ $n=6])$, pollens (7.8\% $[n=4])$, dander (3.1\% [n=2]), and fungi $(1.3 \%[n=1])$. In a similar study by Acharya et al, ${ }^{22}$ house dust followed by wheat dust, cotton dust, and paper dust was found to be common among patients with nasobronchial allergy. Raj et $\mathrm{al}^{5}$ found some different patterns of prevalence of sensitization in North India. In their study, HDM was not the common allergen, but housefly was the commonest allergen (36.7\% [ $n=66]$ ) followed by grain dust (31\% $[n=56])$ and female cockroach $(18.3 \%[n=33])$. A study from abroad, Ibekwe and Ibekwe ${ }^{10}$ observed that HDMs allergen yielded the highest number of positive responses (22.6\% [ $n=43])$ followed by tree pollen $(16.8 \%[n=48])$. The sensitization pattern observed was different from other studies from the same geographical region. An earlier study from North India that assessed 480 asthmatics/allergics found Prosopis juliflora among pollen and Alternaria alternata as important sensitizers with 34.7 and $17.7 \%$ skin positivity, respectively. ${ }^{23}$ Another study from Southern India in patients with nasobronchial allergy showed a high prevalence of mite allergy (73.7\%) and pollen allergy (75.8\%). ${ }^{24}$ The reason for this difference from the same geographical area is probably because of seasonal and annual fluctuations in allergens. Heterogeneity in allergen extract composition can lead to the different patterns of sensitization observed in our study. ${ }^{25}$ The variable composition and content of allergenic extract of different manufacturers may affect the allergenicity of the extract. ${ }^{26}$

The patients in our study were mainly from the urban and semiurban areas surrounding the hospital and belonged to a similar socioeconomic background; differences could not be elicited based on the residence of patients. There were no major changes in the climatic condition or flora and fauna. In a study conducted by Mahesh et $\mathrm{al}^{27}$ on adults, it was found that sensitization patterns did not vary a lot according to different areas of residence except in younger patients. They found higher sensitization to fungi and cockroaches in younger patients from the rural and urban areas, respectively. Our study has opened a new avenue in the field of allergen testing in children and has shown that SPT is very much feasible even in younger age groups when needed. None of the patients suffered any severe reaction, and the most common reaction was mild local itching. However, a medication tray with the provision of adrenaline was always available at our OPD for managing any severe anaphylactic reaction if needed. Large, cross-sectional studies in other settings are required to be conducted to establish the SPT as an easy, cost-effective, and sensitive method of allergen study. It has already been shown by multiple studies that allergen avoidance can lead to a reduction in symptoms in AR and asthma. ${ }^{28}$

The idiopathic rhinitis, intrinsic asthma, and idiopathic urticaria patients with negative SPTs might nevertheless be suffering from allergic causes not detected by the SPTs used. One possible reason could relate to the intrinsic limitations of SPTs themselves (depending on the available allergens and their specificity and affinity for the circulating IgE) ${ }^{29}$ In our study, $1+$ grade $(<3 \mathrm{~mm}$ ) was $46.7 \% .2+$ grade $(3-5 \mathrm{~mm})$ was only $2 \%, 3+$ grade $(5-7 \mathrm{~mm})$ was $23.3 \%$, and $4+$ grade $(>7 \mathrm{~mm})$ was $26.7 \%$. In an Irani study by Gharagozlou et al, ${ }^{30}$ the percentage of grade 2 or more of SPT positivity was $11 \%(n=25)$. Their most cases ( $84 \%[n=196]$ ) had grade 1 positivity, whereas in our study, more than $50 \%(n=60)$ patients were having SPT grade 2 or more. A study by Kumar et $\mathrm{al}^{18}$ found the grading of SPT as 2 or more in $46.75 \%$ ( $n=1993$ ) of cases of respiratory allergy, which is quite similar to the finding of our study.

This study also sets the direction toward allergen avoidance, as depending on the prototype of allergens present in our region, allergen avoidance measures can be suggested to those children in whom SPT could not be performed due to age or other factors. However, the effect of allergen avoidance can be only studied in a separate study conducted over a longer period. The sample population included only the children attending the pediatric OPD of the hospital; therefore, the data may not be representative of the general 
population of the area and the true prevalence of the disease may differ from our data. Another limitation was the small sample size of the population.

\section{Conclusion}

On SPT, HDM (Dermatophagoides pteronyssinus) was positive in maximum number of patients followed by storage mite (Acarus siro). Among pollens, Ambrosia artemisiifolia was the commonest. Avoidance of common inhaled allergens found with SPT in our region in children with allergic airway diseases was advised. Patients may undergo immunotherapy if indicated. Our study did not encounter even a single adverse reaction; this further proves that SPT is quite a safe method.

\section{Ethical Approval}

This study was approved by the Ethical Committee of Mahatma Gandhi Medical College, Jaipur, Rajasthan, India (no. MGHCH/IEC/JPR/2018/05).

\section{Funding}

None.

\section{Conflict of Interest \\ None declared.}

\section{Acknowledgments}

We are thankful to the Department faculty and our patients; without their support this study would not have been possible.

\section{References}

1 Canonica GW, Baena-Cagnani CE, et al. 100 years of immunotherapy: the Monoco Charter. Int Arch Allergy Immunol 2013;160:346-349

2 Braunstahl GJ, Fokkens W. Nasal involvement in allergic asthma. Allergy 2003;58(12):1235-1243

3 Prasad R, Kumar R. Allergy situation in India: what is being done? Indian J Chest Dis Allied Sci 2013;55(01):7-8

4 Koul PA, Patel D. Indian guidelines for asthma: adherence is the key. Lung India 2015;32(Suppl 1):S1-S2

5 Raj D, Lodha R, Pandey A, Mukherjee A, Agrawal A, Kabra SK; New Delhi Childhood Asthma Study Group. Aeroallergen sensitization in childhood asthmatics in northern India. Indian Pediatr 2013;50 (12):1113-1118

6 Huurre TM, Aro HM, Jaakkola JJ. Incidence and prevalence of Asthma and allergic rhinitis: a cohort study of Finnish adolescents. J Asthma 2004;41(03):311-317

7 Prasad R, Verma SK, Dua R, Kant S, Kushwaha RA, Agarwal SP. A study of skin sensitivity to various allergens by skin prick test in patients of nasobronchial allergy. Lung India 2009;26(03):70-73

8 Dave L, Srivastava N. Sensitization pattern to various allergens in UAD. Res J Pharm Biol Chem Sci 2014;5(04):1397-1403

9 Moitra S, Sen S, Datta A, et al. Study of allergenicity spectrum to aero allergens by skin prick testing. Austin J Allergy. 2014;1(01):4

10 Ibekwe PU, Ibekwe TS. Skin prick test analysis in allergic rhinitis patients: a preliminary study in Abuja, Nigeria.J Allergy (Cairo) 2016; 2016:3219104
11 Han YY, Lee YL, Guo YL. Indoor environmental risk factors and seasonal variation of childhood asthma. Pediatr Allergy Immunol 2009;20(08):748-756

12 Sharma RK, Mathur Y, Chhabra G, Luhadia A, Luhadia SK, Dhandoria G. A study of skin sensitivity to various allergens by skin prick test in patients of bronchial asthma and allergic rhinitis. Indian J Allergy Asthma Immunol 2018;32:47-53

13 Spinozzi F, Murgia N, Baldacci S, et al; ARGA study group. Characteristics and predictors of allergic rhinitis undertreatment in primary care. Int J Immunopathol Pharmacol 2016;29(01):129-136

14 Kumar L. Allergies in North India. Indian J Pediatr 1981;48(394): 653-658

15 Kumar R, Saran N, Kumar M, Bisht I, SN G. . Pattern of skin sensitivity to various aero allergens in patients of bronchial asthma / allergic rhinitis. Indian J Allergy, Asthma Immunol I 2012;26(02):66-72

16 Rasool R, Shera IA, Nissar S, et al. Role of skin prick test in allergic disorders: a prospective study in Kashmiri population in light of review. Indian J Dermatol 2013;58(01):12-17

17 Siroux V, Oryszczyn MP, Paty E, et al. Relationships of allergic sensitization, total immunoglobulin $\mathrm{E}$ and blood eosinophils to asthma severity in children of the EGEA Study. Clin Exp Allergy 2003;33(06):746-751

18 Kumar R, Kumar M, Bisht I, Singh K. Prevalence of aeroallergens in patients of bronchial asthma and/or allergic rhinitis in India based on skin prick test reactivity. Indian J Allergy Asthma Immunol 2017;31:45-55

19 Mathur M, Mathur HC. Etiology of asthma in Rajasthan. Indian Pediatr 1987;24(07):549-552

20 Dey S, Chakraborty T. Prevalence study of common environmental allergens in children with asthma and allergic rhinitis in Kolkata: a hospital-based study. Indian J Child Health (Bhopal) 2017;3(03):225-229

21 Duc J, Kolly M, Pécoud A. Frequency of respiratory allergens involved in rhinitis and bronchial asthma in adults. Prospective study [in French]. Schweiz Med Wochenschr 1986;116(36):1205-1210

22 Acharya PJ. Skin test response to some inhalant allergens in patients of nasobronchial allergy from Andhra Pradesh. Aspects Allergy Appl Immunol 1980;8:34-36

23 Sharma S, Kathuria PC, Gupta CK, Nordling K, Ghosh B, Singh AB. Total serum immunoglobulin E levels in a case-control study in asthmatic/allergic patients, their family members, and healthy subjects from India. Clin Exp Allergy 2006;36(08):1019-1027

24 Lal A, Sunaina Waghray S, Nand Kishore NN. Skin prick testing and immunotherapy in nasobronchial allergy: our experience. Indian J Otolaryngol Head Neck Surg 2011;63(02):132-135

25 Casset A, Mari A, Purohit A, et al. Varying allergen composition and content affects the in vivo allergenic activity of commercial Dermatophagoides pteronyssinus extracts. Int Arch Allergy Immunol 2012;159(03):253-262

26 Esch RE. Allergen source materials and quality control of allergenic extracts. Methods 1997;13(01):2-13

27 Mahesh PA, Kummeling I, Amrutha DH, Vedanthan PK. Effect of area of residence on patterns of aeroallergen sensitization in atopic patients. Am J Rhinol Allergy 2010;24(05):e98-e103

28 Passalacqua G, Durham SR; Global Allergy and Asthma European Network. Allergic rhinitis and its impact on asthma update: allergen immunotherapy. J Allergy Clin Immunol 2007;119(04):881-891

29 Pierson-Mullany LK, Jackola DR, Blumenthal MN, Rosenberg A. Evidence of an affinity threshold for IgE-allergen binding in the percutaneous skin test reaction. Clin Exp Allergy 2002;32(01):107-116

30 Gharagozlou M, Rategari V, Movahedi M, Moin M, Hassan BM. Total serum IgE and skin tests in children with respiratory allergy. Tanaffos 2005;15:27-31 